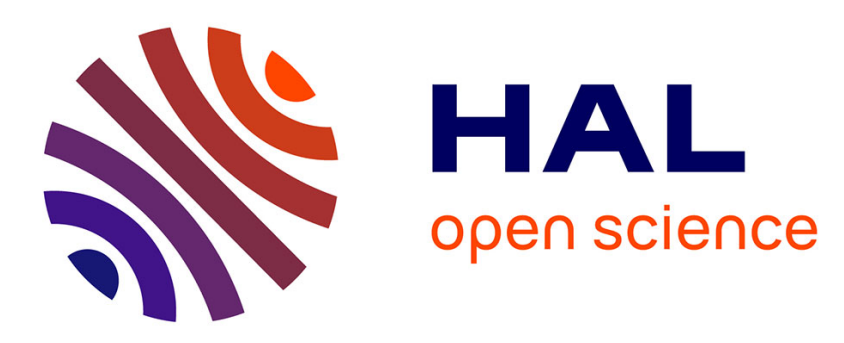

\title{
An experimental study on turbulent premixed expanding flames using simultaneously Schlieren and tomography techniques
}

Pierre Brequigny, Charles Endouard, Christine Mounaïm-Rousselle, Fabrice Foucher

\section{To cite this version:}

Pierre Brequigny, Charles Endouard, Christine Mounaïm-Rousselle, Fabrice Foucher. An experimental study on turbulent premixed expanding flames using simultaneously Schlieren and tomography techniques. Experimental Thermal and Fluid Science, 2018, 95, pp.11 - 17. 10.1016/j.expthermflusci.2017.12.018 . hal-01893580

HAL Id: hal-01893580

https://hal-univ-orleans.archives-ouvertes.fr/hal-01893580

Submitted on 20 Mar 2019

HAL is a multi-disciplinary open access archive for the deposit and dissemination of scientific research documents, whether they are published or not. The documents may come from teaching and research institutions in France or abroad, or from public or private research centers.
L'archive ouverte pluridisciplinaire HAL, est destinée au dépôt et à la diffusion de documents scientifiques de niveau recherche, publiés ou non, émanant des établissements d'enseignement et de recherche français ou étrangers, des laboratoires publics ou privés. 


\title{
Draft:An experimental study on turbulent premixed expanding flames using simultaneously Schlieren and Tomography techniques \\ Pierre Brequigny*, Charles Endouard*, Christine Mounaïm-Rousselle*, Fabrice Foucher* \\ pierre.brequigny@univ-orleans.fr \\ * Univ. Orléans, PRISME, EA 4229, F45072 Orléans, France
}

\begin{abstract}
As in most of industrial cases, in Spark-Ignition (SI) engines, the expansion of premixed flames is strongly affected by turbulence flow fields. However, as the flame radius and curvature are non-negligible during the combustion development, global stretch effect can drastically change the turbulent flame propagation speed. In this paper, spherical turbulent premixed flames are studied inside a constant-volume vessel for a wide range of air-isooctane mixture and initial turbulence by using simultaneously Mie scattering tomography and 2-views Schlieren techniques. With the 2-views Schlieren diagnostic, the flame volume can be reconstructed and a more 'real' flame radius can be determined. The comparison between this radius, which is more usually determined by only 1-view Schlieren, and the one obtained by tomography was possible, and enabled to select non-conveyed flames with a global spherical shape. In the first part, the values of the correction factor for Schlieren images, first introduced by Bradley et al. in 2003, is discussed as function of the turbulent intensity and initial pressure. In the second part, the effect of turbulent intensity and initial pressure for isooctane/air mixtures on flame propagation speed evolution is evaluated as function of the stretch rate.
\end{abstract}

\section{Keywords}

Spherical expanding flame, Turbulent flame speed, iso-octane-air mixture

\section{Introduction}

As expanding turbulent premixed flames occur in Spark Ignition engines, this flame configuration remains an interesting research issue to globally improve Internal Combustion Engines. Specific conditions for premixed flames, such as high pressure, high temperature and 
high diluted environment, are studied nowadays and still require better knowledge of their propagation in both laminar and turbulent regimes. The effect of initial conditions on the laminar burning speed and Markstein length has been previously studied by many authors [15]. The experimental work done with different fuels in a wide range of conditions highlights strong impact of the stretch on flame propagation. As in the work of Karlovitz et al. [6] and Markstein [7], the flame stretch can be easily linked to the laminar flame speed [8-10]. However, the acceleration mechanism in the case of expanding turbulent flames is more complex, since the flame front of turbulent expanding flames is affected both by a mean global stretch rate due to the growth of the mean flame front radius, and by local stretch rates related to the wrinkling of the flame front. Several recent studies [11-17] focused on the flame response to the stretch for different fuels and conditions but investigation is still needed. This paper presents new experimental turbulent flame speed measurements in a constant-volume combustion chamber by using simultaneous Mie-scattering tomography and 2-Views Schlieren technique. Isooctane, usual gasoline surrogate was also chosen due to its dynamic response to stretch between lean and rich conditions. The objective of this paper is twofold. First, by using simultaneously Tomography and a 2 Views Schlieren diagnostic, the correction factor proposed by Bradley et al. [12] to estimate turbulent burning speed from Schlieren images is discussed, and a first correlation to determine this correction factor is proposed. Secondly, the effect of initial pressure on the flame speed as function of stretch, for different turbulent intensities is investigated. And the effect of the correction factor is also discussed.

\section{Experimental set-up}

\subsection{Combustion vessel}

Experiments were conducted in a high-pressure/high-temperature combustion vessel used for both laminar and turbulent premixed flame propagation investigations. Included below is a brief description of the setup; for more details about the preparation of the reactive mixture see 
in [4]. The combustion chamber is a spherical stainless steel vessel with an inner diameter of $200 \mathrm{~mm}$. A heater wire resistance located on the outer surface of the sphere is used to heat initial gases until a maximum temperature of $473 \mathrm{~K}$. The temperature fluctuation of the mixture is estimated less than $2 \mathrm{~K}$ for the target initial temperature. Initial pressure inside the vessel is limited to 10 bar with a maximum deviation between the effective and the set-point initial pressure of about $3 \%$. The isooctane/air mixture is introduced in the vessel by means of different flowmeters [4]. The mixture is ignited by a spark produced between two $0.5 \mathrm{~mm}$ diameter tungsten electrodes with a charge time of the ignition coil fixed to $3 \mathrm{~ms}$ for all cases.

The vessel is equipped with four optical quartz windows providing optical access for the implementation of laser diagnostic techniques. Turbulence is generated by six identical fourblade fans (40 mm diameter) located in a regular octahedral configuration, close to the wall of the combustion chamber. The fans direct the flow toward the center of the vessel. Each fan speed can be accurately adjusted between 1000 and $17000 \mathrm{rpm}$ with an accuracy of $\pm 0.1 \%$. The fans run continuously during combustion propagation.

In previous work [18], the turbulent flow was fully characterized by using Laser Doppler Velocimetry and Particle Imaging Velocimetry in non-reactive conditions. It was particularly shown that the fans generated homogeneous and isotropic turbulence in a central portion of 40 mm diameter. In [18], the turbulence intensity was found to be proportional to the rotational fan speed but the integral length scale $L_{T}$ independent of the fan speed and equal to $3.4 \mathrm{~mm}$.

\section{High speed image acquisition and post-processing}

In the first part of this study, two High Speed (HS) imaging systems were used: first one consists in 2-Views Schlieren one (Fig. 1). Each Schlieren pathway is made by using a LED (CBT120), coupling with a $1 \mathrm{~mm}$ pin-hole to guarantee a point source and two convex metallic mirrors ( $864 \mathrm{~mm}$ focal length). At the focus point of the second mirror, a $0.5 \mathrm{~mm}$ dot is placed 
and two lenses (200 $\mathrm{mm}$ and $160 \mathrm{~mm}$ ) allow the focusing of images directly on the CMOS chip. With this arrangement, both views can be simultaneously recorded with only one HS camera (Phantom v1610) at full resolution (1024x800 pixels $\left.{ }^{2}\right)$ and magnification ratio of $0.1 \mathrm{~mm}$ per pixel. As one objective of this study is to compare the wrinkled radius from the Schlieren images, resulting of 3D integration along the optical pathway and from planar Mie scattering images, a second optical arrangement was set-up. A laser sheet from a HS Nd-Yag laser (Quantronix dual-Hawk HP) passes between both electrodes with a $4^{\circ}$ tilt angle to prevent any interaction with the Schlieren arrangement. A second HS camera mounted with a Scheimpflug and a $200 \mathrm{~mm}$ Nikon macro-lens records Mie scattering images (from silicon oil seeding droplets) with a delay of only $5 \mu$ s relative to Schlieren images to prevent any light interaction. The optical configuration for the first part of the study is identified as "Setup 1". The main advantage of this setup is to select flames that keep a global spherical shape during the propagation and are not conveyed out of the flame sheet, thus enabling to capture a representative contour of the whole flame. With such a technique, it is then possible to determine the correction to be applied to Schlieren images in order to avoid an overestimation of the radius due to the projection of a 3D flame in a 2D plan. In the second part of this study, only one Schlieren view, identified as "Setup 2", was used as it is a simpler setup, but also to improve the correction factor determined from the first study with the Setup 1.

Schlieren and tomographic images were post-processed by using Matlab routines to extract the flame contour. As described in [12], mean flame radius $R_{a}$ is derived from the circle of area equivalent to the flame area inside the contour. $R_{A, S}=\sqrt{A_{S} / \pi}$ and $R_{A, T}=\sqrt{A_{T} / \pi}$ are respectively flame radii determined from Schlieren and tomographic techniques based on flame surface, A and $R_{V, S}=\left(3 V_{S} / 4 \pi\right)^{1 / 3}$ based on the flame volume estimated from 2-Views Schlieren technique is also defined. As shown in Fig. 2, from both side and front views Schlieren images, the flame volume can be determined by the integration of ellipses surface as 
function of the $\mathrm{z}$ direction. These ellipses, indicated in grey in Figure 2, are fitted through four points defined as the four points of both Schlieren contours projection.

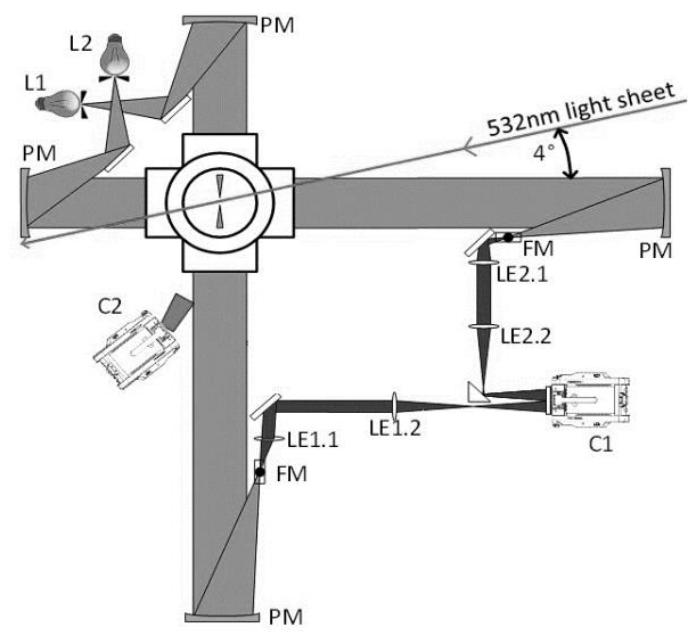

Figure 1. Experimental setup 1. L1 and L2: LED, PM: parabolic mirror, C1 Phantom v1610 Camera, C2 Phantom v1210 Camera, FM: Dot point, LE: Lenses. Setup 2 uses only the optical path coming from L1.



Figure 2. Example of images. (a) front Schlieren image, (b) side Schlieren image, (c) Mie scattering image from the side view, (d) reconstructed flame volume.

The turbulent burning speed is obtained from the time derivation of the temporal evolution of radius flame $V_{T}=d R_{a} / d t$. Because a propagating flame surface undergoes global curvature, local curvature and flow field strain, the total stretch $\kappa$, quantifying the turbulence-flame interaction, can be separated into 3 terms according to Chaudhuri et al. [17]:

$$
\kappa=\overbrace{\text { stretch rate by curvature: } \kappa_{c, R}}^{\underbrace{S_{L} \kappa}_{\text {normal strain rate: } \kappa_{n}}}+\underbrace{\nabla_{t} \cdot \mathrm{v}_{\mathrm{t}}}_{\text {tangential strain rate: } \kappa_{t}}
$$


The first term is due to curvature $\kappa_{\mathrm{c}, \mathrm{R}}$, and the second and third terms of Eq. (1) represent all the stretch rate contributions by the strain rate, $\kappa_{\mathrm{s}}$. The first term $\kappa_{\mathrm{c}, \mathrm{R}}$ could be also split into two parts: the stretch rate due to local wrinkling and the strain rate due to the macroscopic flame shape. In the case of spherical flame propagation, the mean radius of the flame during the first part of the propagation is small but generates strong curvature. This curvature tends to decrease rapidly with the increase of the flame radius. By considering the contribution of flame macroscopic geometry, $\kappa_{\mathrm{c}, \mathrm{R}}$ is defined the same way as for spherical laminar flame :

$$
\kappa_{c, R}=\frac{2}{R_{A}} \frac{d R_{A}}{d t}
$$

\section{Results and discussions}

\subsection{Correction factor estimation}

All investigated experimental conditions using the 2 Views-Schlieren technique simultaneously with Mie-Scattering tomography are summarized in Table 1. Mixtures were selected because the unstretched laminar burning speed $S_{L}{ }^{0}$ is the same but Lewis numbers $L e_{e f f}$ and Markstein lengths $L_{b}$ are different. $S_{L}^{0}$ and $L_{b}$ were obtained using data and correlations from previous studies $[4,19,20]$ except for $\Phi=1.46$ where Markstein length was not determined due to high cellularity and the correlation is not usable. Lewis numbers were calculated using the method of Bechtold and Matalon [21]. A synthetic EGR (Exhaust Gas Recirculation) mixture was used with $12.4 \% \mathrm{CO}_{2}, 14 \% \mathrm{H}_{2} \mathrm{O}$ and $73.6 \% \mathrm{~N}_{2}$ in volume. All flames can be considered between the thin reaction zone and the corrugated flamelet zone, in the flamelet regime from Borghi-Peters diagram [22,23]. In order to validate the use of an equivalent radius obtained from the surface of Schlieren contours to estimate turbulent flame speed, the mean radii $\left(R_{A, S}, R_{A, T}, R_{V, S}\right)$ are displayed in Figure 3 . They are given with an uncertainty of $+/-0.2$ $\mathrm{mm}$ at 1 bar and +/- $0.5 \mathrm{~mm}$ at 5 bar. 


\begin{tabular}{|c|c|c|c|c|c|c|c|c|c|c|}
\hline $\begin{array}{c}\mathrm{P} \\
(\mathrm{MPa})\end{array}$ & $\Phi$ & $\begin{array}{c}\mathrm{EGR} \\
\%\end{array}$ & $\begin{array}{c}S_{L}{ }^{0} \\
(\mathrm{~cm} / \mathrm{s})\end{array}$ & $\begin{array}{c}\mathrm{u}^{\prime} \\
(\mathrm{m} / \mathrm{s})\end{array}$ & $\begin{array}{c}L_{b} \\
(\mathrm{~mm})\end{array}$ & $L e_{\text {eff }}$ & $\begin{array}{c}\delta_{L} \\
{[\mu \mathrm{m}]}\end{array}$ & $u^{\prime} / S_{L}{ }^{0}$ & $L_{T} / \delta_{L}$ & $\begin{array}{c}\text { Correction } \\
\text { factor for } \\
\text { Schlieren data }\end{array}$ \\
\hline 0.1 & 0.8 & 0 & 39.2 & 0.52 & 1.1 & 2.52 & 95 & 1.33 & 35.8 & 0.77 \\
\hline 0.1 & 0.8 & 0 & 39.2 & 1.04 & 1.1 & 2.52 & 95 & 2.65 & 35.8 & 0.70 \\
\hline 0.1 & 0.8 & 0 & 39.2 & 1.39 & 1.1 & 2.52 & 95 & 3.55 & 35.8 & 0.684 \\
\hline 0.5 & 0.8 & 0 & 28.3 & 0.52 & 0.34 & 2.52 & 26 & 1.84 & 130.8 & 0.715 \\
\hline 0.5 & 0.8 & 0 & 28.3 & 1.04 & 0.34 & 2.52 & 26 & 3.67 & 130.8 & 0.68 \\
\hline 0.1 & 1.0 & 0 & 53.6 & 0.52 & 0.78 & 1.98 & 67.8 & 0.97 & 50.1 & 0.791 \\
\hline 0.1 & 1.0 & 0 & 53.6 & 1.04 & 0.78 & 1.98 & 67.8 & 1.94 & 50.1 & 0.73 \\
\hline 0.1 & 1.0 & 0 & 53.6 & 1.39 & 0.78 & 1.98 & 67.8 & 2.59 & 50.1 & 0.71 \\
\hline 0.1 & 1.0 & 7.5 & 39.4 & 0.52 & 1 & 2 & 93 & 1.32 & 36.6 & 0.71 \\
\hline 0.1 & 1.0 & 7.5 & 39.4 & 1.04 & 1 & 2 & 93 & 2.64 & 36.6 & 0.71 \\
\hline 0.1 & 1.0 & 7.5 & 39.4 & 1.39 & 1 & 2 & 93 & 3.53 & 36.6 & 0.724 \\
\hline 0.5 & 1.0 & 7.5 & 28.4 & 0.52 & 0.27 & 2 & 26 & 1.83 & 130.8 & 0.77 \\
\hline 0.5 & 1.0 & 7.5 & 28.4 & 1.04 & 0.27 & 2 & 26 & 3.66 & 130.8 & 0.67 \\
\hline 0.1 & 1.46 & 0 & 39.2 & 0.52 & -1.5 & 1.3 & 88 & 1.33 & 38.6 & 0.795 \\
\hline 0.1 & 1.46 & 0 & 39.2 & 1.04 & -1.5 & 1.3 & 88 & 2.65 & 38.6 & 0.705 \\
\hline
\end{tabular}

Table 1. Experimental conditions for the Setup 1

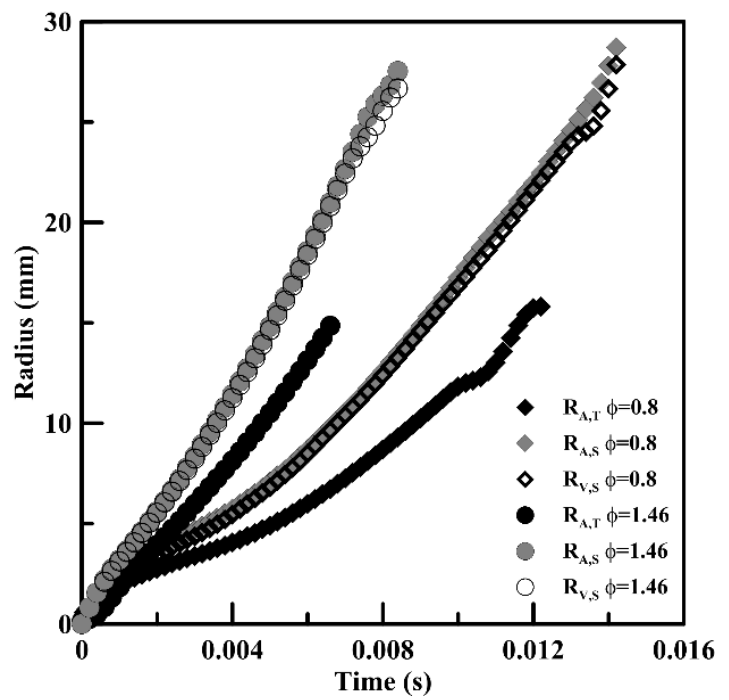

Figure 3. Example of different radii time evolution for lean and rich mixtures $(\mathrm{P}=0.1 \mathrm{MPa}$, $\left.\mathrm{T}=423 \mathrm{~K}, \mathrm{u}^{\prime}=1.04 \mathrm{~m} / \mathrm{s}\right)$.

First, it is interesting to note that no difference is distinguishable between the radius obtained from 2-Views or 1-View Schlieren technique. This confirms that the equivalent radius evolution obtained with 1-View Schlieren technique enables to characterize the whole volume. On the other hand, radii calculated from tomography are smaller than those from Schlieren technique due to the difference in these optical techniques themselves: 2D cut or 3D projection. Moreover the present set-up enables us to select flames that are not conveyed out of the laser 
sheet plan and that keeps globally a spherical shape during the propagation in order to properly determine a correction factor for the Schlieren images. Indeed, Bradley et al. [12] suggested to correct the radius by a correction factor $C$ as $R_{A}=C . R_{A, S}$. This correction factor is calculated by averaging the ratio of the tomographic flame speed to the Schlieren flame speed on the flame propagation duration as follows:

$$
C=\left\langle\frac{d \overline{R_{A, T}}}{d \overline{R_{A, S}}}\right\rangle_{\text {propagation }}
$$

Because the mean curvature stretch is although linked to the flame radius, the correcting radius will be used and in the case of Schlieren images, turbulent propagation speed and $\kappa_{\mathfrak{c}, \mathrm{R}}$ become:

$$
\begin{aligned}
& V_{T}=\frac{d\left(C \cdot R_{A, S}\right)}{d t} \\
& \kappa_{C, R}=\frac{2}{C \cdot R_{A, S}} \frac{d\left(C \cdot R_{A, S}\right)}{d t}
\end{aligned}
$$

For all conditions investigated, this coefficient is between 0.7 and 0.8 for 1 bar and between 0.65 and 0.8 bar for 5 bar instead of the value of 0.9 determined by Bradley et al. [12]. Several reasons can explain this difference. First the definition of the tomography mean radius is different for both studies. Second, in this work, both techniques, tomography and Schlieren diagnostics, are simultaneous. Last, the fuel is not the same: propane vs. isooctane, which can produce different levels of wrinkling.

Table 1 also shows that the correction factor decreases with the increase of the ratio of turbulent intensity to the unstretched laminar burning speed. As a result, to properly account for the effect of turbulence and flame properties, a correlation is proposed in Fig.4 for the correction factor $C$ as a function of $u^{\prime} / S_{L}{ }^{0}$ which appears to be the most impacting parameter in Table 1. The correction factor can be then calculated as follows:

$$
C=a * \frac{u^{\prime}}{S_{L}^{0}}+b
$$


With $a=-3.55 \cdot 10^{-2}$ and $b=0.84$.

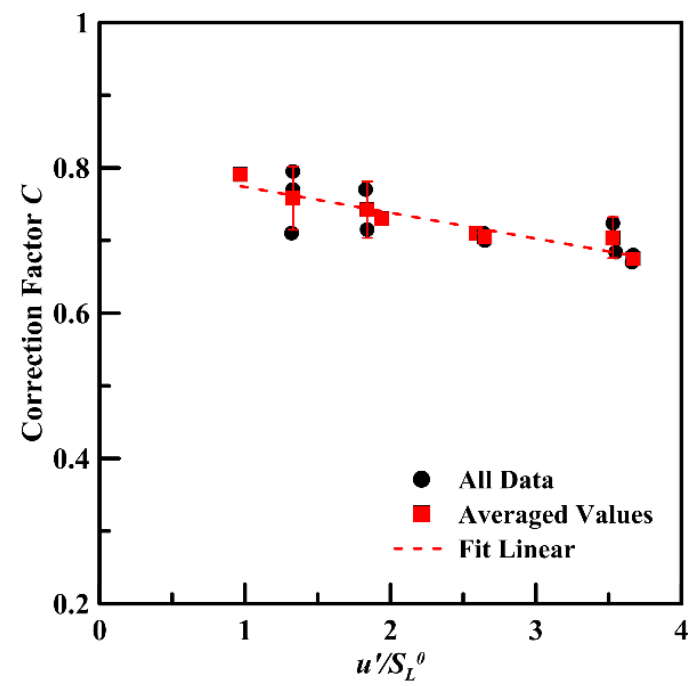

Figure 4. Correction factor as function of $u^{\prime} / S_{L}{ }^{0}$

From Fig. 4, the validity of the correlation can be discussed especially for low $u$ ' $/ S_{L}{ }^{0}$. Indeed in laminar conditions, the correction factor should be equal to 1 because the flame is not wrinkled by the turbulence and as a result the radius obtained by both optical techniques should be similar since there is no flame brush in such conditions. Some investigations are therefore required for values of $u^{\prime} / S_{L}^{0}$ between 0 and 1 and experiments will be carried out in future work for such conditions. 


\subsection{Influence of initial conditions on flame propagation and the validity of the correlation for the optical correction factor}

To study the influence of each initial parameter separately and the validity of the correlation, the conditions presented in Table 2 were investigated using a single Schlieren view diagnostic as described before. The following results were corrected using the correlation shown in Fig.4.

\begin{tabular}{|c|c|c|c|c|c|c|c|c|c|}
\hline $\begin{array}{c}P \\
(\mathrm{MPa})\end{array}$ & $\Phi$ & $\begin{array}{c}u^{\prime} \\
(\mathrm{m} / \mathrm{s})\end{array}$ & $\begin{array}{c}S_{L}{ }^{0} \\
(\mathrm{~cm} / \mathrm{s})\end{array}$ & $\begin{array}{c}L_{b} \\
(\mathrm{~mm})\end{array}$ & $L e$ & $\begin{array}{c}\delta_{L} \\
(\mu \mathrm{m})\end{array}$ & $u^{\prime} / S_{L}^{0}$ & $L_{T} / \delta_{L}$ & $\begin{array}{c}\lambda \\
(\mathrm{mm})\end{array}$ \\
\hline 0.1 & 1.0 & 1.39 & 53.6 & 0.78 & 1.98 & 67.8 & 2.59 & 50.1 & 0.99 \\
\hline 0.1 & 1.0 & 0.69 & 53.6 & 0.78 & 1.98 & 67.8 & 1.29 & 50.1 & 1.40 \\
\hline 0.1 & 1.0 & 1.04 & 53.6 & 0.78 & 1.98 & 67.8 & 1.94 & 50.1 & 1.15 \\
\hline 0.1 & 1.0 & 1.73 & 53.6 & 0.78 & 1.98 & 67.8 & 3.23 & 50.1 & 0.89 \\
\hline 0.1 & 1.0 & 2.08 & 53.6 & 0.78 & 1.98 & 67.8 & 3.88 & 50.1 & 0.81 \\
\hline 0.1 & 1.0 & 2.43 & 53.6 & 0.78 & 1.98 & 67.8 & 4.53 & 50.1 & 0.75 \\
\hline 0.3 & 1.0 & 1.39 & 42.9 & 0.36 & 1.98 & 28.3 & 3.24 & 120.1 & 0.57 \\
\hline 0.5 & 1.0 & 1.39 & 38.7 & 0.25 & 1.98 & 18.8 & 3.59 & 180.9 & 0.44 \\
\hline 1 & 1.0 & 1.39 & 33.6 & $0.15^{*}$ & 1.98 & 10.8 & 4.14 & 314.8 & 0.31 \\
\hline
\end{tabular}

Table 2. Experimental conditions investigated with Setup 2. $\lambda \sim L_{T}\left(15 / R e_{L}\right)^{0.5}$. Symbols (*) indicate that values are estimated from the correlation in [20].

\subsubsection{Turbulence intensity effect}

Fig.5 shows the corrected turbulent flame speed as a function of the corrected equivalent radius. The flame speed increase as a function of the radius can be explained by the increase of the wrinkling ratio as shown in Fig.6. Indeed the turbulent intensity increase is responsible for an increase of the wrinkling and therefore of the turbulent flame speed. This rise of the wrinkling is mainly provoked by the decrease of the small turbulent scales as already shown by Galmiche et al. [18] and Brequigny et al. [24] on the same vessel. Moreover it is important to notice that the flame radius observed here are quite small below $20 \mathrm{~mm}$. Usually when the flame reaches the full spectrum of turbulence, the curve of flame speed as function of radius reaches a plateau [25]. In this case, due to the small size of the windows (60 $\mathrm{mm}$ diameter) and the small size of the spherical HIT zone (40 $\mathrm{mm}$ diameter), it is not possible to observe flame radius 
greater than $20 \mathrm{~mm}$ for the best cases, i.e. without any displacement of the initial flame kernel. As a consequence, the flame is not yet impacted by the full spectrum of turbulence. Also, it can be seen that the increase of the slope of the turbulent flame speed with the turbulence intensity appears to be limited for $\mathrm{u}^{\prime}$ greater than $1.73 \mathrm{~m} / \mathrm{s}$. This is mainly due to the fact that the small turbulent length scales, i.e. Taylor and Kolmogorov reach a plateau for u' higher than $1.73 \mathrm{~m} / \mathrm{s}$.

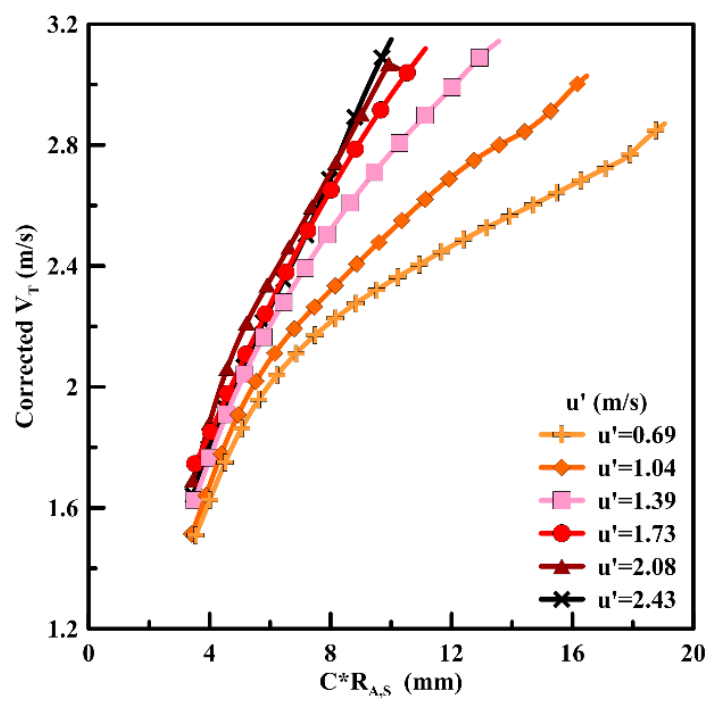

Figure 5. Corrected flame speed as a function of flame radius for different turbulent intensities obtained from corrected Schlieren data. $P=0.1 \mathrm{MPa}, T=423 \mathrm{~K}, \boldsymbol{\Phi}=\mathbf{1 . 0}$.

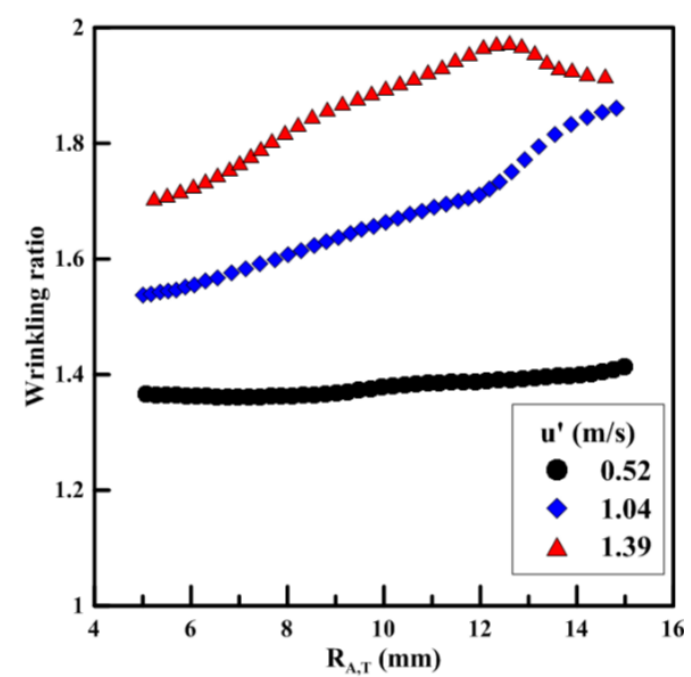

Figure 6. Wrinkling ratio as a function of flame radius obtained from Mie scattering images for turbulent intensities. $P=0.1 \mathrm{MPa}, T=423 \mathrm{~K}, \boldsymbol{\Phi}=\mathbf{1 . 0}$.

Moreover, as isooctane is known as a flame stretch sensitive fuel contrary to the methane (Jiang et al. [25]), the flame stretch generated by both flame expansion and turbulence will then delay the flame speed increase during the propagation [15,24] especially for small radii 
corresponding to high flame stretch. Considering the flame speed as function of the flame stretch can then highlight those effects. In Fig.7.b, it can be seen how the corrected turbulent flame speed trajectory as function of stretch is close to the nonlinear model used to describe laminar cases in same conditions [20]. When the turbulent intensity increases, the agreement with nonlinear laminar extrapolation model is less convincing. Therefore the flame kernel develops first like in laminar conditions before being impacted by the turbulence in a second phase.

To evaluate the impact of the correlation to correct the Schlieren data, Fig. 7 shows the same plot for non-corrected and corrected Schlieren data (Fig. 7.a and 7.b respectively).Without any correction, it can be seen that the flame speed trajectory is close to the nonlinear extrapolation model only at low turbulent intensity. When increasing u', the flame speed and flame stretch increase thus moving the trajectory in the upper right part of the graph. When applying the correlation for the correction factor to the flame speed, all the curves move towards the nonlinear extrapolation of the corresponding laminar case. The flame speed seems then to follow a laminar development before being impacted by the turbulence and overpassing the laminar curve especially for u' higher than $1.04 \mathrm{~m} / \mathrm{s}$. For comparison purpose, the corrected values obtained from the correction proposed by Bradley et al. [12] are added in Fig. 7b. It can be noticed the Bradley et al. correction enables to decrease the flame speed as for the correction proposed in the present paper but moreover values are shifted towards higher stretch levels. This due to the impact of the correction proposed by Bradley et al. on flame stretch since the radius is corrected using the following relation $0.9 * R_{A}-2.1$ thus modifying the stretch value calculated from Eq. 2. 

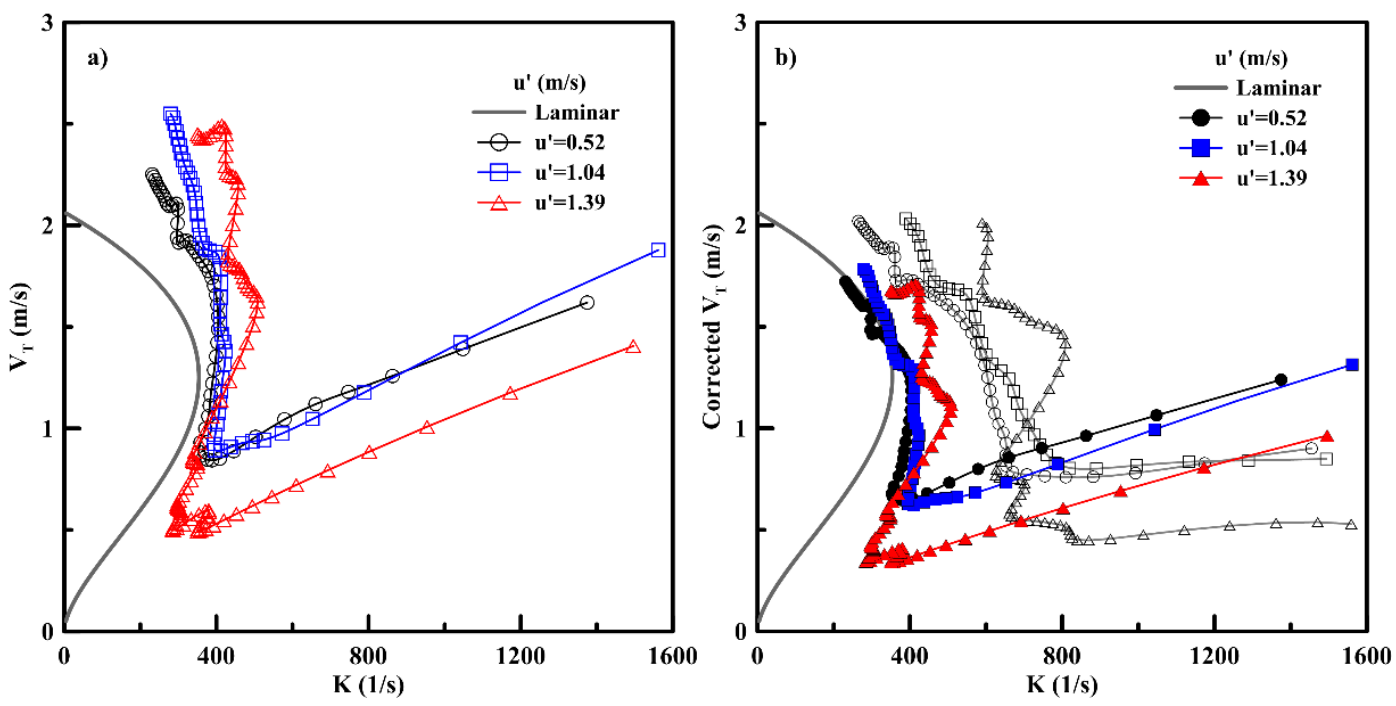

Figure 7. Flame speed as a function of flame stretch for all the turbulent intensities with noncorrected (a) and corrected (b: empty symbols corresponds to Bradley et al. correction, filled symbol corresponds to Eq. 6) Schlieren data. Grey line: nonlinear laminar extrapolation model for the same initial conditions. $\boldsymbol{P}=0.1 \mathrm{MPa}, T=423 \mathrm{~K} ; \boldsymbol{\Phi}=0.8$.

\subsubsection{Pressure effect}

The effect of the initial pressure on the turbulent flame speed is shown on Fig. 8. The increase of the turbulent flame speed due the pressure increase can be also explained by the augmentation of the wrinkling ratio. Galmiche et al. [18] showed that the increase of initial pressure in the vessel induces a decrease of the small turbulent length scales, i.e. Taylor and Kolmogorov length scales, especially between 1 and 5 bar. After 5 bar, the small length scales reach a plateau [18], which can explain the non-effect on the flame speed. Moreover, the flame thickness decreases also with the pressure as seen in Table 2, so this enlarges the turbulent scales spectrum that can wrinkle the flame towards the small length scales and leads to an increase of wrinkling and therefore the flame speed. 


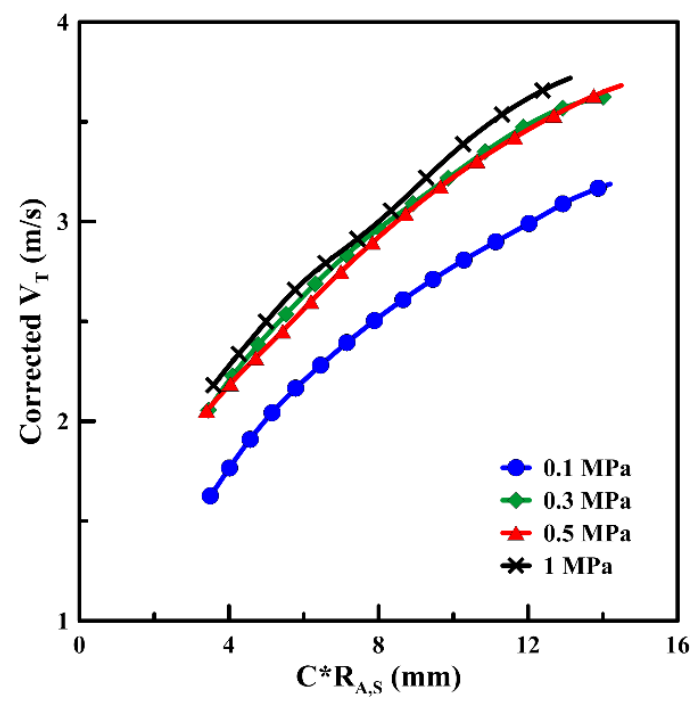

Figure 8 - Propagation flame versus flame radius obtained from corrected Schlieren data. $T=423 \mathrm{~K}, \boldsymbol{\Phi}=1.0, u^{\prime}=1.39 \mathrm{~m} / \mathrm{s}$.
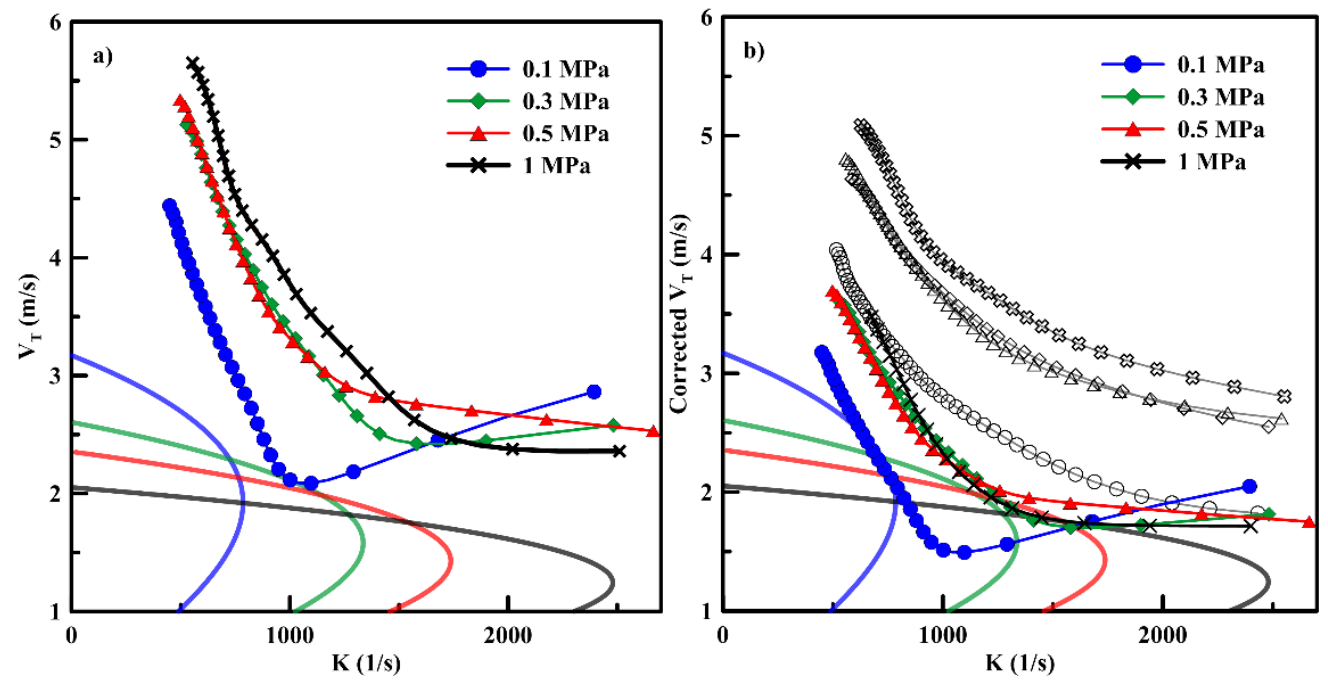

Figure 9. Flame speed versus flame stretch for different initial pressures non-corrected (a) and corrected (b: empty symbols corresponds to Bradley et al. correction, filled symbol corresponds to Eq. 6). Continuous lines: nonlinear laminar extrapolation model for the same initial conditions. $T=423 \mathrm{~K}, \boldsymbol{\Phi}=1 ; u^{\prime}=1.39 \mathrm{~m} / \mathrm{s}$.

Fig. 9 shows the flame speed as a function of flame stretch for both non corrected (Fig. 9.a) and corrected (Fig. 9.b) Schlieren data in order to evaluate in terms of pressure the validity of the correlation with the correction factor presented in Fig. 4. Flame speed as a function of stretch first decreases or presents a flat evolution before showing an inflexion point and finally increases for low stretch levels due to the turbulence and wrinkling that accelerates the flame front. When applying the correction on the Schlieren data, it passes close to the laminar extrapolation model even for the case of 10 bar of pressure, which was not used to determine 
the correlation in Fig.4. The correction brought to the Schlieren data here is in agreement with the evolution of flame speed as a function of flame stretch observed in Fig. 7. The turbulent flame speed presents an evolution similar to the laminar flame speed and is strongly impacted by the flame stretch before being accelerated thanks to turbulence and wrinkling. Again corrected values obtained from the correction of Bradley et al. are added to Fig. $9 \mathrm{~b}$ for comparison purpose.

\section{Conclusion}

In this paper, Mie scattering tomography and Schlieren techniques were set to evaluate the correction factor suggested by Bradley et al. [12] in order to ensure the validity of the turbulent propagation flame speed estimate from Schlieren images. First, by using the 2-Views Schlieren set-up, has been reconstructed in order to confirm the accuracy of the radius value determined by only one view and its ability to describe the flame propagation. Then by comparing both Schlieren and tomography radii, the correction factor to correct the flame speed obtained from Schlieren images has been estimated. Values between 0.65 and 0.8 were determined, not constant and below the constant value of 0.9 previously determined by Bradley et al. A correlation has been proposed to estimate the correction factor depending on turbulent and flame properties, i.e. $u^{\prime} / S_{L}{ }^{0}$. Future work will focus on improving this correlation especially for lower turbulent intensities as well as several pressures and dilution.

In the second part of the paper, the correction factor was applied to the flame speed and radius obtained from 1-View Schlieren technique. The use of this correlation shows that the evolution of the flame speed as a function of flame stretch displays a laminar-like evolution, especially in the early flame development before turbulence acts on the flame front and accelerates the flame. This behaviour is similar to the evolution observed with Mie-scattering tomography thus confirming the importance of correcting Schlieren data. 
Finally the influence of turbulent intensity and pressure was investigated in terms of flame speed as function of radius or as function of stretch to better understand the dynamic of the flame propagation for the improvement of Spark-Ignition engine modelling. Various optical diagnostics combined with the deep turbulent characterization done in previous work [18] were used to propose a detailed analysis of the influence of each parameter on the flame propagation and therefore on the optical correction required.

\section{Acknowledgements}

This work was financed by the MACDOC project from the French National Research Agency, ANR-12-VPTT-0008.

\section{References}

[1] D. Bradley, R.A. Hicks, M. Lawes, C.G.W. Sheppard, R. Woolley, The Measurement of Laminar Burning Velocities and Markstein Numbers for Iso-octane-Air and Isooctane-n-Heptane-Air Mixtures at Elevated Temperatures and Pressures in an Explosion Bomb, Combust. Flame. 115 (1998) 126-144. doi:10.1016/S00102180(97)00349-0.

[2] D. Bradley, M. Lawes, K. Liu, M.S. Mansour, Measurements and correlations of turbulent burning velocities over wide ranges of fuels and elevated pressures, Proc. Combust. Inst. 34 (2013) 1519-1526. doi:10.1016/j.proci.2012.06.060.

[3] D. Bradley, M. Lawes, M.S. Mansour, Explosion bomb measurements of ethanol-air laminar gaseous flame characteristics at pressures up to $1.4 \mathrm{MPa}$, Combust. Flame. 156 (2009) 1462-1470. doi:10.1016/j.combustflame.2009.02.007.

[4] B. Galmiche, F. Halter, F. Foucher, Effects of high pressure, high temperature and dilution on laminar burning velocities and Markstein lengths of iso-octane/air mixtures, Combust. Flame. 159 (2012) 3286-3299. doi:10.1016/j.combustflame.2012.06.008. 
[5] B. Galmiche, F. Halter, F. Foucher, P. Dagaut, Effects of Dilution on Laminar Burning Velocity of Premixed Methane/Air Flames, Energy \& Fuels. 25 (n.d.) 948-954. http://dx.doi.org/10.1021/ef101482d.

[6] B. Karlovitz, D.W. Denniston, D.H. Knapschaefer, F.E. Wells, Studies on Turbulent flames, Symp. Combust. 4 (1953) 613-620. doi:10.1016/S0082-0784(53)80082-2.

[7] G.H. Markstein, Non-steady Flame Propagation, Pergamon Press, 1964.

[8] P. Clavin, Dynamic behavior of premixed flame fronts in laminar and turbulent flows, Prog. Energy Combust. Sci. 11 (1985) 1-59. doi:10.1016/0360-1285(85)90012-7.

[9] Z. Chen, Y. Ju, Theoretical analysis of the evolution from ignition kernel to flame ball and planar flame, Combust. Theory Model. 11 (2007) 427-453. http://dx.doi.org/10.1080/13647830600999850.

[10] F. Halter, T. Tahtouh, C. Mounaïm-Rousselle, Nonlinear effects of stretch on the flame front propagation, Combust. Flame. 157 (2010) 1825-1832. doi:10.1016/j.combustflame.2010.05.013.

[11] R.G. Abdel-Gayed, D. Bradley, M. Lawes, Turbulent Burning Velocities: A General Correlation in Terms of Straining Rates, Proc. R. Soc. London. A. Math. Phys. Sci. . 414 (1987) 389-413. doi:10.1098/rspa.1987.0150.

[12] D. Bradley, M.Z. Haq, R.A. Hicks, T. Kitagawa, M. Lawes, C.G.W. Sheppard, et al., Turbulent burning velocity, burned gas distribution, and associated flame surface definition, Combust. Flame. 133 (2003) 415-430. doi:10.1016/S0010-2180(03)000397.

[13] L. Gillespie, M. Lawes, C.G.W. Sheppard, R. Woolley, Aspects of Laminar and Turbulent Burning Velocity Relevant to SI Engines, SAE Tech. Pap. (2000). doi:10.4271/2000-01-0192.

[14] B. Renou, A. Boukhalfa, An Experimental Study of Freely Propagating Premixed 
Flames at Various Lewis Numbers, Combust. Sci. Technol. 162 (2001) 347-370. doi:10.1080/00102200108952148.

[15] P. Brequigny, F. Halter, C. Mounaïm-Rousselle, Lewis number and Markstein length effects on turbulent expanding flames in a spherical vessel, Exp. Therm. Fluid Sci. 73 (2016) 33-41. doi:10.1016/j.expthermflusci.2015.08.021.

[16] S. Chaudhuri, F. Wu, D. Zhu, C.K. Law, Flame Speed and Self-Similar Propagation of Expanding Turbulent Premixed Flames, Phys. Rev. Lett. 108 (2012) 44503. http://link.aps.org/doi/10.1103/PhysRevLett.108.044503.

[17] S. Chaudhuri, A. Saha, C.K. Law, On flame-turbulence interaction in constantpressure expanding flames, Proc. Combust. Inst. 35 (2015) 1331-1339. doi:10.1016/j.proci.2014.07.038.

[18] B. Galmiche, N. Mazellier, F. Halter, F. Foucher, Turbulence characterization of a high-pressure high-temperature fan-stirred combustion vessel using LDV, PIV and TRPIV measurements, Exp. Fluids. 55 (2013) 1-20. doi:10.1007/s00348-013-1636-x.

[19] G. Broustail, F. Halter, P. Seers, G. Moréac, C. Mounaïm-Rousselle, Experimental determination of laminar burning velocity for butanol/iso-octane and ethanol/iso-octane blends for different initial pressures, Fuel. 106 (2013) 310-317. doi:10.1016/j.fuel.2012.10.066.

[20] C. Endouard, F. Halter, C. Chauveau, F. Foucher, Effects of CO2, H2O, and Exhaust Gas Recirculation Dilution on Laminar Burning Velocities and Markstein Lengths of Iso-Octane/Air Mixtures, Combust. Sci. Technol. 188 (2016) 516-528. doi:10.1080/00102202.2016.1138792.

[21] J.K. Bechtold, M. Matalon, The dependence of the Markstein length on stoichiometry, Combust. Flame. 127 (2001) 1906-1913. http://www.sciencedirect.com/science/article/pii/S0010218001002978. 
[22] R. Borghi, Mise au point sur la structure des flammes turbulentes, J. Chim. Phys. 81 (1984) 361-370. http://cat.inist.fr/?aModele=afficheN\&cpsidt=8873264 (accessed July 29, 2014).

[23] N. Peters, Laminar flamelet concepts in turbulent combustion, Symp. Combust. 21 (1988) 1231-1250.

http://www.sciencedirect.com/science/article/pii/S0082078488803552.

[24] P. Brequigny, F. Halter, C. Mounaïm-Rousselle, T. Dubois, Fuel performances in Spark-Ignition (SI) engines: Impact of flame stretch, Combust. Flame. 166 (2016) 98112. doi:10.1016/j.combustflame.2016.01.005.

[25] L.J. Jiang, S.S. Shy, W.Y. Li, H.M. Huang, M.T. Nguyen, High-temperature, highpressure burning velocities of expanding turbulent premixed flames and their comparison with Bunsen-type flames, Combust. Flame. 172 (2016) 173-182. doi:10.1016/j.combustflame.2016.07.021. 